\title{
Dissociative Experiences and Psychopathology Among Inmates in Italian and Portuguese Prisons
}

International Journal of Offender Therapy and Comparative Criminology $1-18$

(C) The Author(s) 2015

Reprints and permissions: sagepub.com/journalsPermissions.nav DOI: $10.1177 / 0306624 X 15617256$ ijo.sagepub.com

(SAGE

\section{Giulio Cesare Zavattini ', Carlo Garofalo',2, Patrizia Velotti ${ }^{3}$, Marco Tommasi ${ }^{4}$, Roberta Romanelli4, Helena Espírito Santo5, Mara Costa ${ }^{5}$, and Aristide Saggino ${ }^{4}$}

\begin{abstract}
The association between dissociation and psychopathological symptoms is well established, yet studies with inmates are lacking. If higher rates of dissociation and psychiatric symptoms are reported in inmate samples, it is not clear whether they represent two separate, albeit related, characteristics. We examined the association between dissociation and psychopathological symptoms among 320 Italian subjects (122 inmates and 198 community participants) and a Portuguese inmate sample $(n=67)$. Then, we tested whether dissociation and psychopathology levels were higher among inmates. Both hypotheses were supported, confirming the relevance of dissociative, paranoid, and psychotic symptoms among inmates, as well as their interrelations. Notably, the group difference in dissociation remained significant after partialing out the variance associated with other psychopathological symptoms. Conversely, only the difference in paranoid symptoms remained-marginallysignificant when controlling for the influence of dissociation. This finding suggests that dissociation may have unique relevance for the psychological functioning of inmates.
\end{abstract}

\section{Keywords}

dissociation, psychopathology, inmates, Italy, Portugal

\footnotetext{
ISapienza University of Rome, Italy

${ }^{2}$ Tilburg University, The Netherlands

${ }^{3}$ University of Genoa, Italy

${ }^{4}$ University of Chieti-Pescara, Italy

5 Miguel Torga Institute, Coimbra, Portugal

Corresponding Author:

Patrizia Velotti, Department of Education Sciences, University of Genoa, Corso Andrea Podestà, 2,

16126, Genoa, Italy.

Email: patrizia.velotti@unige.it
} 


\section{Introduction}

Dissociation involves the alteration in those functions that allow an integration of the self, including identity, memory, consciousness, affectivity, perception, and cognition (American Psychiatric Association, 2013; Bernstein \& Putnam, 1986). The construct of dissociation, especially as measured by the most widely used questionnaire (i.e., the Dissociative Experiences Scale [DES]; Bernstein \& Putnam, 1986), seems stable across different cultural contexts, in terms of presence and degree of presentation in various countries (Barker-Collo, 2001; Bauer \& Power, 1995; Collins \& Jones, 2004; Espirito-Santo \& Abreu, 2009; Garofalo et al., 2015; Larøi, Billieux, Defeldre, Ceschi, \& Van der Linden, 2013; Lipsanen, Saarijärvi, \& Lauerma, 2003; Ross, Joshi, \& Currie, 1991; Spitzer, Freyberger, \& Stieglitz, 1998; Xiao et al., 2006). The positive association between dissociation and psychopathological symptoms is also well established in a broad range of nonclinical (Bauer \& Power, 1995; Levin \& Spei, 2004; Maaranen et al., 2008; Maaranen et al., 2005; Martínez-Taboas \& Bernal, 2000; Mulder, Beautrais, Joyce, \& Fergusson, 1998) and clinical populations (Allen, Coyne, \& Console, 1996, 1997; Belli, Ural, Vardar, Yesılyurt, \& Oncu, 2012; Bob et al., 2008; Espirito-Santo, Gonçalves, Marques, Rocha, \& Cassimo, 2013; Lewis-Fernandez et al., 2002; Löffler-Stastka, Szerencsics, \& Blüml, 2009; Modestin, Ebner, Junghan,

\& Erni, 1996; Oedegaard et al., 2008; Rufer, Fricke, Held, Cremer, \& Hand, 2005; Sar et al., 2007; Schäfer et al., 2011; Schäfer et al., 2007; Simões, Espirito-Santo, Jesus, \& Marques, 2014; Somer, Altus, \& Ginzburg, 2010). Notably, the association that has been more consistently replicated regards the correlation between dissociative and psychotic symptoms (Allen \& Coyne, 1995; Allen et al., 1997; Barker-Collo, 2001; Lysaker \& LaRocco, 2008; Sar et al., 2010; Simões et al., 2014). Taking a closer look at the dissociation literature, one could conclude that there is a disproportion of samples recruited, with a landslide majority of studies involving clinical, community, and student samples (e.g., Evren et al., 2013; Foote, Smolin, Kaplan, Legatt, \& Lipschitz, 2006; Gutiérrez Wang, Cosden, \& Bernal, 2011; Maaranen, 2008; Maaranen et al., 2005; Van IJzendoorn, 1996; Vogel, Spitzer, Barnow, Freyberger, \& Grabe, 2006; Xiao et al., 2006; Yoshizumi, Murase, Murakami, \& Takai, 2007), and only a handful of them addressing dissociation in offender samples (Ciulla \& Caretti, 2012; Dietrich, 2003; Lancaster, Compton, White, Bowers, \& Herring, 1998; Lewis, Yeager, Swica, Pincus, \& Lewis, 1997; Mitchell, 2006; Ruiz, Poythress, Lilienfeld, \& Douglas, 2008; Walker, 2002). Although inmates often present with higher rates of dissociative symptoms (Barker-Collo \& Moskowitz, 2005; Dietrich, 2003; Espirito-Santo \& Costa, 2013; McLeod, Byrne, \& Aitken, 2004; Snow \& Beckman, 1996), and dissociation itself has been reported as a risk factor for antisocial and violent behavior in offender populations (Dietrich, 2003; Moskowitz, 2004; Poythress, Skeem, \& Lilienfeld, 2006), there is a lack of studies exploring the associations of dissociation with external correlates in these populations. Some of them (e.g., Ruiz et al., 2008; Spitzer et al., 2001) supported the relationship of dissociation with antisocial behavior and aggression, as well as with early traumatic experiences. Notably, in most studies, inmate samples reached a mean score on dissociation scales equal to those of clinical samples, except 
those with diagnosed Dissociative Disorder (i.e., a mean score around 18; see, for example, Espirito-Santo \& Costa, 2013; McLeod et al., 2004; Moskowitz, BarkerCollo, \& Ellson, 2005; Ruiz et al., 2008; Van IJzendoorn, 1996). However, only a few studies have investigated the association between dissociative symptoms and psychopathological disease among inmates (Moskowitz et al., 2005). They have reported a high correlation between dissociation and psychotic symptoms as assessed with the Symptom Checklist-90-Revised (Derogatis, 1994), along with other smaller correlations with various forms of psychiatric symptoms, as well as with general psychopathological distress. Based on these findings, Moskowitz et al. (2005) proposed that dissociative experiences may either predispose or underlie some psychiatric especially psychotic_-symptoms. Indeed, they argued that at least some psychiatric symptoms could be driven by dissociative mechanisms, and thus should be considered dissociative in nature. Also, Allen et al. (1997) asserted that dissociative experiences may constitute a vulnerability for psychotic and other psychopathological experiences by depriving a person of external and internal "anchors." Therefore, whether dissociative symptoms and other forms of psychopathological disease represent two distinct but related factors remains relatively unexplored. Information on their association may be particularly important in prison settings, where dissociative and psychopathological symptoms are usually overrepresented. Knowing whether dissociation goes hand in hand (at least to a certain extent) with other psychopathological symptoms that are more often assessed in prison settings (i.e., general form of psychopathology) could ultimately help to refine treatment programs for inmates. Unfortunately, to the best of our knowledge, this has not been empirically tested yet. Indeed, whether dissociative experiences may (at least partially) account for and explain the presence of psychiatric symptoms in general, and psychotic symptoms, in particular, is still an open question. In other terms, previous studies did not report if differences in dissociative experiences remained significant when accounting for the influence of psychiatric symptoms, and vice versa. According to the models reviewed above (Allen et al., 1997; Moskowitz et al., 2005), it could be expected that levels of dissociation would remain significantly higher among inmates after controlling for other psychopathological symptoms, while dissociation could account for the levels of psychopathology. Indeed, if dissociation would underlie psychopathological symptoms (e.g., psychotic symptoms, see Moskowitz et al., 2005), when controlling for the influence of each other, only dissociation (but not other psychopathological symptoms) should account for a significant portion of the difference between the inmate and the community sample. In other words, if dissociation and psychopathological symptoms are related, it may be that group differences on them actually depend on their shared variance, rather than reflecting a difference on both dimensions.

Finally, notwithstanding the excellent reliability, the good validity, and the wellestablished stability across cultures of the DES (Espirito-Santo \& Abreu, 2009; Van IJzendoorn, 1996), there is a dearth of studies on the DES and its correlates directly comparing samples from different countries and different settings simultaneously, and this is especially true in Europe (Spitzer et al., 2006). Specifically, to our knowledge, there are no studies available that have compared cross-culturally dissociative 
symptoms or the dissociation-psychosis link, let alone cross-cultural comparison gathering data from different samples, such as inmates. Thus, another controversial issue regards the actual comparability of results across studies belonging to different countries and targeting different populations. Moreover, scant attention has been paid to the generalizability of findings derived from a specific country, for example, comparing in the same study similar populations from different countries.

The present study aimed to address most of the controversial issues mentioned above. First, in line with previous findings (Espirito-Santo \& Costa, 2013; Mitchell, 2006; Moskowitz et al., 2005; Ruiz et al., 2008; Snow \& Beckman, 1996), we expected that inmates reported higher degrees of dissociative experiences than controls. Then, we sought to corroborate evidence of the relationships between dissociative and other psychiatric symptoms. Particularly, based on the extant literature (Allen et al., 1997; Moskowitz et al., 2005; Watson, 2001), we expected to replicate previous findings attesting to the strong correlation between the DES total score and self-reported psychotic symptoms above and beyond other significant relations (Lysaker \& LaRocco, 2008), both in community and offender samples. Furthermore, we wanted to test whether dissociation explained higher levels of psychopathological symptoms among inmates, and if the degree of dissociative experiences would remain significantly higher among inmates after accounting for the influence of other forms of psychopathology. Finally, to avoid capitalizing on the characteristics of a single offenders group belonging to a given country, we confronted rates of both dissociative symptoms and psychopathological disease in an Italian and a Portuguese inmate samples. It is worth noting that we used the DES total score only because the DES has two different factorial structures in Italy (Garofalo et al., 2015) and Portugal (Espirito-Santo \& Abreu, 2009). Moreover, because the factorial structure of the DES mostly varies across different populations, the authors themselves suggested using the total score for research purpose (e.g., Bernstein \& Putnam, 1986). The present study also adds to the literature on the factorial models of the DES, by examining the DES-II factorial structures in the two inmate samples, seeking evince for confirming in the Portuguese sample the two-factor model recently reported for the Italian version of the DES-II (Garofalo et al., 2015).

\section{Method}

\section{Participants}

The Italian sample consisted of 320 individuals, including 122 inmates convicted of violent offenses $(M$ age $=39.97$ years, $S D=11.76$ years $)$ and 198 controls $(M$ age $=$ 32.51 years, $S D=10.30$ years); most of them were males (inmates $=98 \%$, controls $=$ $58.6 \%$ ). To test cross-cultural differences between Italian and Portuguese inmates, we compared the data of the Italian inmates with a sample composed by 67 Portuguese inmates, with an average age of 34.85 years $(S D=8.98$ years $)$. All Portuguese inmates were males, and $37.3 \%(n=25)$ committed violent crimes. Portuguese inmates were younger than inmates of the Italian sample $(t=3.43, p<.01)$. All participants in both the samples were Caucasians. 


\section{Procedures}

After the study received approval from the Ethics Board Research of the "Sapienza" University of Rome and the Italian Ministry of Justice, the Italian participants in the control group were enrolled through local advertisement posted online and throughout the community, requesting potential volunteers for psychological studies. The Italian inmate group consisted of individuals recruited from different jails and prisons located around two big Italian cities (Rome and Genoa), which filled out the measures and an informed consent to voluntarily take part in the study.

For the Portuguese inmate sample, participants were recruited from a highsecurity correctional facility within the Centro region. Attendance to psychological and medical consultations, and an informational poster were used to inform the inmates about the study, and those who manifested interest were selected for the study. Participants could request a follow-up psychological consultation if distressed by issues evoked by the questionnaires (three of them required this followup). Respondents were interviewed individually in the psychological consultation room over one session lasting approximately $1 \mathrm{hr}$. Inmates were initially informed about the study, their rights, and asked to sign an informed consent form. Then, a trained clinical psychologist orally administered all measures. The Miguel Torga Higher Institute and correctional agency Research Review Boards and Committees approved the whole procedure.

Participation was entirely voluntary, no payment was offered, answers were entirely anonymous and confidential, and there was no coercion for the subjects, especially inmates, to participate.

\section{Measures}

The DES-Revised (DES-II). The DES-II (Carlson \& Putnam, 1993) is a self-report scale measuring 28 dissociative phenomena in daily life related to depersonalization, derealization, amnesia, and absorption. Respondents are asked to indicate on $100-\mathrm{mm}$ visual analogue scales to what extent they experience these phenomena, without being under the influence of alcohol or drugs. Each analogue scale ranges from $0 \%$, meaning never, to $100 \%$, meaning at least once per week (containing 11 options at $10 \%$ increments). The total DES-II score is the mean of all 28 items scores. Original research demonstrated that DES-II has high reliability (test-retest $=.79<r<.84$; split-half $=.83<r<.93$; Cronbach's $\alpha=.95$; Carlson \& Putnam, 1993). Consistent with these findings, both the Italian DES-II version/translation (Cronbach's $\alpha=.91$; split-half: $r=.92$; Fabbri Bombi, Bertin, Cristante, \& Colombo, 1996) and the Portuguese version (Cronbach's $\alpha=.94$; Espirito-Santo $\&$ Abreu, 2009) were reliable. In the present study, we used the Italian translation reported by Conti (1999), which showed excellent internal consistency in previous research (Cronbach's $\alpha=.95$, Garofalo et al., 2015). Our data showed excellent internal consistencies of the DES-II in both samples (Italian sample: Cronbach's $\alpha=.95$; Portuguese sample: Cronbach's $\alpha=.93$ ). 
The Brief Symptom Inventory (BSI). The BSI (Derogatis, 1975; Derogatis \& Melisaratos, 1983 ) is a 53-item short-form version of the Symptom Checklist-90-R (Derogatis, 2011). It is a self-report measure of psychological distress and items from nine orthogonal subscales, including Somatization (SOM), Obsession-Compulsion (O-C), Interpersonal Sensitivity (I-S), Depression (DEP), Anxiety (ANX), Hostility (HOS), Phobic Anxiety (PHOB), Paranoid Ideation (PAR), and Psychoticism (PSY). It also includes three global indexes: the Positive Symptom Total (PST), the Positive Symptom Distress Index (PSDI), and the Global Severity Index (GSI). PST is the number of symptoms endorsed in a pathological direction without considering intensity. PSDI provides information about the severity of distress the respondent experiences. GSI combines the number of endorsed symptoms and their severity. Possible scores range from 0 (not at all) to 4 (extremely), with higher scores indicating greater severity. When answering, subjects are asked to consider the past 30 days including the present day. As to the BSI reliability and validity, Derogatis and Melisaratos (1983) showed that its internal consistency (Cronbach's $\alpha$ ) for each of the nine subscales ranged between .71 (PSY) and .85 (DEP), and test-retest varying from .68 (SOM) and 0.91 (PHOB). In our study, Cronbach's alphas for the whole scale in the Italian sample $(\alpha=$ $.95)$, and in the Portuguese sample $(\alpha=.90)$ were good.

\section{Statistical Analyses}

Correlations between DES-II and BSI subscales and differences between inmates and controls. Correlations between DES-II and psychiatric symptoms measured by BSI were estimated separately for inmates and controls. A test for heterogeneity of correlations (Brown, $1997)$ between inmates and controls was performed. This test is based on the estimation of a statistic $\left(X^{2}\right)$, which approaches a chi-square distribution with $k-1$ degrees of freedom ( $k$ is the number of groups). If $X^{2}$ is significant $(p<.05)$ then the correlations are different.

To test whether there were significant differences between inmates and controls, we carried on multiple $t$ tests. The principal risk of performing multiple $t$ tests is the inflation or first type error (Howell, 2012). The classical procedure, Bonferroni's test, to correct first type error, results to be a strongly conservative test, especially when many comparisons should be performed (Curran-Everett, 2000). A valid alternative is the False Discovery Rate Procedure (Benjamini \& Hochberg, 1995). According to this procedure, estimated probability values $\left(d^{*}\right)$ for each $t$ test are compared with empirical probability values $(p)$. If $p<d^{*}$ then the difference is considered significant.

To explore the unique associations between group status (i.e., community participants vs. inmates) and both DES-II and BSI scores, over and above the influence of the other, the DES-II total score and relevant BSI scale scores were used as covariates in ANCOVA/MANCOVA designs testing between-group differences in the other variable.

Cross-cultural differences between DES-II and BSI subscales. To test whether there were cross-cultural differences in inmates' populations, multiple $t$ tests with the 
False Discovery Rate Procedure (Benjamini \& Hochberg, 1995) were performed. In addition, we conducted a confirmatory factorial analysis of the Portuguese DES-II to compare factorial structures between the different cultures (see Garofalo et al., 2015, for details on the Italian factorial structure).

\section{Results}

\section{Correlations Between DES-II and BSI Subscales and Differences Between Inmates and Controls}

Descriptive statistics for outcome measures of both inmates and controls are presented in Table 1. We also displayed the multiple $t$ tests for BSI subscales, BSI global indices, and global score of DES-II.

According to the False Discovery Rate Procedure, $p$ values of each $t$ test should be compared with corrected probabilities $\left(d^{*}\right)$. If $p<d^{*}$, then the test is significant. Table 1 shows that only the Psychoticism (PSYCHOT) and PAR subscales were significant. Inmates expressed psychotic and paranoid symptoms at a greater level than controls. In addition, PSDI of BSI was significantly different between inmates and controls. Therefore, this index can be used to compare the general impairment attributable to psychiatric symptoms between inmates and normal participants. Finally, the two groups showed a significant difference in DES-II score: The inmates reported more experiences of dissociative symptoms than controls.

Table 2 shows the correlations between the DES-II total score and BSI subscales and general indices (GSI, PST, and PSDI). Correlations were estimated separately for Italian inmates and controls. Because eight inmates did not respond contemporarily to all BSI subscales items, they were excluded from the original group of 122 inmates. An analysis of heterogeneity of correlations (Brown, 1997) was applied to test whether correlations significantly differ between groups.

All correlations between BSI subscales and global indices were identical both for inmates and controls, except for the I-S subscale, in which controls showed a lower correlation in comparison with inmates. Therefore, group affiliation did not affect correlations between DES-II and BSI subscales.

A subsequent ANCOVA revealed that, after controlling for the variance explained by PSYCHOT, PAR, GSI, and PSDI scores, the main effect of group on DES-II total score remained significant, $F(1,307)=8.439, p<.01, \eta_{\text {partial }}^{2}=.027$, with inmates reporting higher levels of dissociative experiences. Thus, a significant, unique, association between the DES-II total score and group status was found. On the other hand, when partialing out the variance associated with the DES-II (Pillai $V=0.334, p<$ $.001)$, a significant multivariate effect of group emerged for the BSI scales included (Pillai $V=0.119 p<.001$ ). However, the univariate effect was significant only for the PAR scale, $F(1,307)=4.332, p<.05, \eta_{\text {partial }}^{2}=.014$, whereas the between-group differences in PSYCHOT, PSDI, and GSI were non-significant (all $p \mathrm{~s}>.05$ ). Accordingly, DES-II total score mediated (i.e., accounted for by) between-group differences on these three scales. 
Table I. Means, SDs, and Multiple t-Test Comparisons (With False Discovery Rate Procedure) for BSI Scales and DES-II Total Score Between Italian Inmates and Controls.

\begin{tabular}{|c|c|c|c|c|c|c|c|}
\hline \multirow[b]{2}{*}{ Variables } & \multicolumn{2}{|c|}{ Inmates $(n=1 \mid 4)$} & \multicolumn{2}{|c|}{ Controls $(n=198)$} & \multirow[b]{2}{*}{$t$} & \multirow[b]{2}{*}{$p$} & \multirow[b]{2}{*}{$d^{*}$} \\
\hline & $M$ & $S D$ & $M$ & $S D$ & & & \\
\hline PHOB & 0.33 & 0.54 & 0.35 & 0.63 & -0.25 & .597 & .050 \\
\hline ANX & 0.90 & 0.84 & 0.86 & 0.80 & 0.45 & .328 & .046 \\
\hline PST & 22.85 & 13.45 & 22.04 & 13.60 & 0.51 & .305 & .042 \\
\hline$O-C$ & 0.92 & 0.91 & 0.86 & 0.74 & 0.64 & .262 & .039 \\
\hline HOST & 0.81 & 0.98 & 0.74 & 0.75 & 0.64 & .261 & .035 \\
\hline$I-S$ & 0.89 & $\mathrm{I} .4 \mathrm{I}$ & 0.76 & 0.93 & 1.01 & .156 & .031 \\
\hline$D E P$ & 0.98 & 0.88 & 0.85 & 0.79 & 1.35 & .090 & .027 \\
\hline SOM & 0.70 & 0.79 & 0.57 & 0.65 & 1.49 & .068 & .023 \\
\hline GSI & 0.84 & 0.73 & 0.70 & 0.63 & 1.80 & .037 & .019 \\
\hline PSDI & 1.69 & 0.66 & 1.46 & 0.54 & 3.17 & .001 & .015 \\
\hline PSYCHOT & 0.90 & 0.87 & 0.57 & 0.66 & 3.51 & .000 & .012 \\
\hline PAR & 1.05 & 0.86 & 0.68 & 0.73 & 3.80 & .000 & .004 \\
\hline DES-II & I 7.74 & 15.02 & 11.45 & 13.10 & 3.73 & .000 & .008 \\
\hline
\end{tabular}

Note. Comparisons are ordered from the comparison with the highest $p$ value to the comparison with the lowest $p$ value. $d^{*}=$ critical significance level. If $p<d^{*}$, then the remaining $i$ null hypotheses are rejected. For ease of presentation, variables on which the two groups showed a significant difference are shown in bold. BSI = Brief Symptom Inventory; DES-II = Dissociative Experiences Scale-II total score; $\mathrm{PHOB}=$ Phobic Anxiety; ANX = Anxiety; PST = Positive Symptom Total; O-C = Obsession-Compulsion; HOST = Hostility; I-S = Interpersonal Sensitivity; DEP = Depression; SOM = Somatization; GSI = Global Severity Index; PSDI = Positive Symptom Distress Index; PSYCHOT = Psychoticism; PAR = Paranoid Ideation.

\section{Cross-Cultural Differences Between DES-II and BSI Subscales}

Table 3 shows the descriptive statistics (means and standard deviations) both for Italian and Portuguese inmates and the multiple $t$ test for BSI subscales, BSI global indices, and global score of DES-II. Thirty-two Portuguese inmates answered to Depression, Anxiety, and Stress Scales instead of BSI, and because of that, they were not included in BSI comparisons. Student $t$ test did not show significant cross-cultural differences between Italian and Portuguese inmates. Only scores on the PAR subscale of BSI were significant, where Portuguese inmates were higher than Italian inmates. The global scores of DES-II do not show a significant cross-cultural difference between Italian and Portuguese inmates.

In addition, we compared the DES-II factors between the two samples. The hypothesized two-model structure of the Italian version (Garofalo et al., 2015) was tested with a confirmatory factorial analysis of Portuguese DES-II, and it was showed a remarkable similitude with the Italian version (Garofalo et al., 2015). Portuguese Factor 1 (compartmentalization) included items 1, 2, 5, 6, 9, 10, 11, 14, 15, 17, 18, 19, 20, 22, 23, 24, and 26. Factor 2 (detachment) comprised items 3, 4, 7, 8, 12, 13, 16, 21 , 25,27 , and 28. Items differences between the Italian and Portuguese versions were as follows. Item 5 (finding new things among personal belongings) and item 11 (looking 
Table 2. Correlations of BSI Subcales and Global Indices (GSI, PST, and PSDI) With DES-II Scores, for Italian Inmates $\left(r_{\text {inmates }}\right)$ and Controls $\left(r_{\text {controls }}\right)$.

\begin{tabular}{lccccccc}
\hline & $r_{\text {inmates }}$ & $r_{\text {controls }}$ & $Z_{\text {inmates }}$ & $Z_{\text {controls }}$ & $Z$ & $\chi^{2}$ & $p$ \\
\hline SOM & .45 & .44 & .48 & .47 & .47 & 0.01 & .920 \\
O-C & .55 & .54 & .61 & .59 & .60 & 0.03 & .873 \\
I-S & .57 & .33 & .64 & .34 & .45 & 6.66 & .010 \\
DEP & .49 & .41 & .54 & .44 & .47 & 0.71 & .398 \\
ANX & .54 & .41 & .60 & .43 & .49 & 2.22 & .136 \\
HOST & .43 & .53 & .46 & .59 & .54 & 1.34 & .247 \\
PHOB & .59 & .47 & .67 & .51 & .57 & 1.89 & .170 \\
PAR & .52 & .48 & .57 & .52 & .54 & 0.19 & .666 \\
PSYCHOT & .58 & .49 & .66 & .53 & .58 & 1.20 & .274 \\
GSI & .64 & .53 & .75 & .59 & .65 & 1.94 & .164 \\
PST & .53 & .38 & .59 & .40 & .46 & 2.61 & .106 \\
PSDI & .52 & .49 & .58 & .53 & .55 & 0.17 & .680 \\
\hline
\end{tabular}

Note. The table also shows Fisher transformations of correlation coefficients for both inmates $\left(Z_{\text {inmates }}\right)$ and controls $\left(Z_{\text {controls }}\right)$ and the test for homogeneity of correlations. $Z=$ average $Z$ value between groups; $\chi^{2}=$ statistic which approaches a chi-square distribution with $k$ - I degrees of freedom ( $k$ is the number of groups); $p=$ probabilities associated with $\chi^{2}$. For ease of presentation, the only variable reporting a significant $p$ value is shown in bold. BSI = Brief Symptom Inventory; GSI = Global Severity Index; PST = Positive Symptom Total; PSDI = Positive Symptom Distress Index; DES-II = Dissociative Experiences Scale-II total score; SOM = Somatization; O-C = Obsession-Compulsion; I-S = Interpersonal Sensitivity; DEP = Depression; ANX = Anxiety; HOST = Hostility; PHOB = Phobic Anxiety; PAR = Paranoid Ideation; PSYCHOT = Psychoticism.

in a mirror and not recognizing) was in Factor 2 in the Italian version, and items 16 (familiar place seems strange), 21 (talk out loud when alone), and 25 (evidences of doing things not remembering doing) were in Factor 1 in the Italian study (Garofalo et al., 2015). The full list of dissociative experiences listed in the DES-II items is reported in Table 4.

\section{Discussion}

Our study showed that our samples' scores were in line with normative data reported in the literature worldwide, concerning the presence and severity of dissociation in both normal (Carlson \& Putnam, 1993; Carlson, Putnam, \& Ross, 1993; EspiritoSanto \& Abreu, 2009; Spitzer et al., 2006; Stockdale, Gridley, Balogh, \& Holtgraves, 2002) and offender populations (Moskowitz et al., 2005; Ruiz et al., 2008; Snow \& Beckman, 1996; Van IJzendoorn, 1996). Interestingly, as expected, inmates reported higher rates of dissociative experiences compared with healthy subjects dwelling in the community, along with few other differences of general psychiatric symptomatology (as assessed with the BSI). Moreover, these results were consistent with a Portuguese inmate sample, suggesting that the relevance of dissociation for the mental health of prisoners was not related to the particular Italian context. This evidence suggests that dissociation may represent a distinctive feature of incarcerated individuals, 
Table 3. Multiple t-Test Comparisons (False Discovery Rate Procedure) for Each BSI Subscale and Global Index, and for DES-II.

\begin{tabular}{|c|c|c|c|c|c|c|c|}
\hline \multirow[b]{2}{*}{ Variables } & \multicolumn{2}{|c|}{$\begin{array}{l}\text { Italian inmates } \\
\quad(n=114)\end{array}$} & \multicolumn{2}{|c|}{$\begin{array}{l}\text { Portuguese inmates } \\
\qquad(n=67 / 33)^{\mathrm{a}}\end{array}$} & \multirow[b]{2}{*}{$t$} & \multirow[b]{2}{*}{$p$} & \multirow[b]{2}{*}{$d^{*}$} \\
\hline & $M$ & $S D$ & $M$ & $S D$ & & & \\
\hline$O-C$ & 0.92 & 0.91 & 0.93 & 0.58 & -0.97 & .923 & .050 \\
\hline SOM & 0.70 & 0.79 & 0.72 & 0.60 & -0.15 & .883 & .046 \\
\hline PSYCHOT & 0.90 & 0.87 & 0.88 & 0.59 & 0.18 & .858 & .042 \\
\hline DES-II & 17.74 & 15.02 & 19.44 & 14.25 & 0.35 & .731 & .039 \\
\hline$I-S$ & 0.89 & 1.41 & 1.04 & 0.51 & -0.60 & .547 & .035 \\
\hline HOST & 0.81 & 0.98 & 0.96 & 0.86 & -0.82 & .416 & .031 \\
\hline$D E P$ & 0.98 & 0.88 & 1.19 & 0.87 & -1.19 & .237 & .027 \\
\hline ANX & 0.90 & 0.84 & 1.05 & 0.52 & -0.12 & .224 & .023 \\
\hline GSI & 0.84 & 0.73 & 1.01 & 0.47 & -1.27 & .207 & .019 \\
\hline PHOB & 0.33 & 0.54 & 0.52 & 0.65 & -0.17 & .097 & .015 \\
\hline PSDI & 0.169 & 0.66 & 1.91 & 0.47 & -1.81 & .073 & .012 \\
\hline PST & 22.85 & 13.45 & 27.06 & 9.97 & -1.96 & .054 & .008 \\
\hline PAR & 1.05 & 0.86 & 1.63 & 0.65 & -0.36 & .001 & .004 \\
\hline
\end{tabular}

Note. Descriptive statistics for all study variables in both Italian and Portuguese inmate samples are reported. $t=$ student $t$ test; $p=$ nominal significance level; $d^{*}=$ corrected probability. For ease of presentation, the only variable reporting a significant difference is shown in bold. BSI = Brief Symptom Inventory; DES-II = Dissociative Experiences Scale-II total score; O-C = Obsession-Compulsion; SOM = Somatization; PSYCHOT = Psychoticism; I-S = Interpersonal Sensitivity; HOST = Hostility; DEP = Depression; ANX = Anxiety; GSI = Global Severity Index; PHOB = Phobic Anxiety; PSDI = Positive Symptom Distress Index; PST = Positive Symptom Total; PAR = Paranoid Ideation.

aThe Portuguese sample included 67 participants in DES comparisons, and 33 in BSI comparisons (the remaining 34 were assessed using the Depression Anxiety Stress Scale-2 I/DASS-2I). We converted GSI and DASS-2I scores into $T$ scores and created a new composite score. The new $t$-test analysis revealed, again, a non-significant difference $(t=1.32 ; p=.188)$.

so that they suffer from dissociative symptoms as much as patients with psychiatric disorders (e.g., van IJzendoorn \& Schuengel, 1996). It is worth noting that inmates also reported higher rates of psychotic and paranoid symptoms if compared with controls. However, our findings add to the extant literature by demonstrating that the between-group difference in psychotic symptoms was accounted for by levels of dissociation. In line with Moskowitz et al.'s (2005) model, this result provides partial support for the underlying role of dissociation in psychotic symptoms. However, after controlling for the influence of general psychopathological distress, as well as of paranoid and psychotic symptoms, the unique relevance of dissociative experiences among inmates remained significant. In the wake of these findings confirming an overrepresentation - and a unique relevance — of dissociation among inmates, we suggest that mental health services in prison should include an evaluation of dissociative symptoms in their standard assessment for newly incarcerated individuals, as well as during the period of imprisonment. This seems particularly important given the other results 
Table 4. Dissociative Experiences Listed in the DES-II Items.

DES-II items content

I. Driving a car and realizing one does not remember part of the trip

2. Missing part of a conversation

3. Finding oneself in a place but unaware of how one got there

4. Finding oneself dressed in clothes one does not remember putting on

5 . Finding unfamiliar things among one's belongings

6. Being called with a different name by people one does not know

7. Seeing oneself as if looking at another person

8. Not recognizing friends or family members

9. Not remembering important events in one's life

10. Being accused of lying when one is telling the truth

II. Not recognizing one's reflection in a mirror

12. Other people and objects do not seem real

13. Feeling as though one's body is not one's own

14. Remembering past so vividly one seems to be reliving it

15. Not sure if remembered event happened or was a dream

16. Being in a familiar place but finding it unfamiliar

17. Absorption in television program or movie

18. So involved in fantasy that it seems real

19. Able to ignore pain

20. Staring into space

21. Talking out loud to oneself when alone

22. Feeling as though one were two different people

23. Usually difficult things can be done with ease and spontaneity

24. Not sure whether one has done something or only thought about it

25. Finding evidence of having done things one cannot remember doing

26. Finding notes or drawings that one must have done but does not remember doing

27. Hearing voices inside one's head

28. Looking at the world through a fog

Note. DES-II = Dissociative Experiences Scale-II.

that we reported, confirming the strong association between dissociative and other psychiatric symptoms. In line with previous findings (Moskowitz et al., 2005), the degree of self-reported dissociation was significantly related to a variety of psychopathological symptoms across different domains, as well as with the overall severity of general symptomatology. However, in both the community and inmate Italian samples, differences among correlation coefficients linking each type of psychiatric symptom (i.e., BSI subscales) with the DES-II total score, were too slight to hazard selective associations with specific domains more than others (as stated by Moskowitz et al., 2005 , about psychotic symptoms). It is noteworthy that, to our knowledge, this is the first study testing for statistical differences in the correlation patterns for the dissociation-general psychopathology associations, comparing an inmate sample with a 
control group. Interestingly, our data did provide evidence of invariability across the two samples, about relations mentioned above between dissociative and other psychopathological symptoms. This implies that, regardless the severity, dissociation is likely to represent a symptom highly associated with — and perhaps underlying — other forms of psychopathological disease, instead of representing an isolated sign. As such, assessing dissociative experiences may help in understanding (and treating) the general psychiatric burden reported by incarcerated offenders. Indeed, along with information regarding symptomatic manifestation (e.g., psychotic symptoms), a focus on dissociative tendencies could represent an additional (and potentially relevant) piece of information regarding inmates' psychological mechanisms. Further research could help to understand the causal direction of this association with longitudinal designs, as well as to highlight the underlying mechanism and the clinical implications of these relations.

Another purpose of this study was to compare the factorial model of the Italian DES-II with data from the Portuguese sample, to promote a reliable comparison of the dissociation construct across cultures, at least as assessed with the DES. A two-factor model provided the best fit for the Italian sample (Garofalo et al., 2015). Results with the Portuguese sample provided evidence for the replicability of this two-factor model. It is also noteworthy that items 5, 11, 16, 21, and 25 (see Table 4 for information on items content) loaded on a different factor across the two samples, possibly because of differences in contextual aspects of the prisons of both countries. The differences in paranoid symptoms between the two samples (with statistical significant higher values in the Portuguese inmates), could also reflect these differences, suggesting that Italian prisons are perceived as safer by inmates. As a whole, it seems that a bi-dimensional conceptualization of dissociation is valid across cultures.

Some limitations of the study should be taken into consideration and addressed in future research. First, we neither assessed for possible psychiatric diagnosis affecting the inmate participants nor knew whether they were taking psychotropic medication at that moment. ${ }^{1}$ Thus, we cannot exclude that the inmates' higher level of psychotic symptoms was due to an actual overlap with psychotic conditions, instead of representing the effect of captivity. However, it is noteworthy that Ruiz et al. (2008) argued that the degree of psychotic symptoms among inmates is roughly equal across countries. Thus, this limitation does not preclude the possibility for further replication of our results. Nevertheless, in future studies, it would be useful to exclude those inmates with diagnosed psychotic disorders, or to compare those receiving psychotropic medication with those that are not pharmacologically treated.

Second, our assessment methodology included only self-report measures, limiting our ability to reduce measurement bias, although DES-II and BSI are extensively used measures, with well-established psychometric properties. The replication of our findings by adding a structured interview for dissociative experiences might be useful to overcome measurement bias (Ross, Heber, Norton, \& Anderson, 1989; Steinberg, Cicchetti, \& Buchanan, 1993). Third, this study used a cross-sectional design and thus did not allow an investigation of causal relationships. Moreover, conflicting findings across different samples point out the issue of whether results obtained within a 
specific sample can be generalized to other populations (Cima, Merckelbach, Klein, Shellbach-Matties, \& Kremer, 2001; Spitzer et al., 2003; Van IJzendoorn \& Schuengel, 1996). This is particularly true regarding offender samples, where a number of confounding variables may affect the external validity of the DES. For example, according to Snow and Beckman (1996), inmates' dissociative states may represent either a dissociative psychopathology or a temporarily activated defense mechanism induced by their peculiar environment (i.e., the condition of incarceration) . Other authors have proposed that it could also reflect faking or malingering (McLeod et al., 2004). Future research is encouraged to control for these possible confounding factors.

Finally, several authors argued that traumatic experiences may act as antecedents of dissociative symptoms (e.g., Aydin \& Altindag, 2009; Foote et al., 2006; Gutiérrez Wang et al., 2011; Nilsson, Gustafsson, \& Svedin, 2010). Further studies, aiming to understand dissociative phenomena among inmates, should integrate the assessment of traumatic events.

In conclusion, our results corroborate the relevance of considering dissociative symptoms in their relation with general symptomatology and psychopathological distress, highlighting the alarming severity of dissociative symptoms in prisoners. Moreover, these data are validated across different samples from different countries. Hence, another important implication of our findings is the importance of providing interventions to reduce dissociative symptomatology among the inmate population.

\section{Declaration of Conflicting Interests}

The author(s) declared no potential conflicts of interest with respect to the research, authorship, and/or publication of this article.

\section{Funding}

The author(s) received no financial support for the research, authorship, and/or publication of this article.

\section{Note}

1. However, none of the participants were in an acute phase of any psychiatric disorder (i.e., requiring admission to the mental health section at their prison, or to a psychiatric facility outside the prison) at the time of the study.

\section{References}

Allen, J. G., \& Coyne, L. (1995). Dissociation and vulnerability to psychotic experience: The Dissociative Experiences Scale and the MMPI-2. Journal of Nervous and Mental Disease, 183, 615-622.

Allen, J. G., Coyne, L., \& Console, D. A. (1996). Dissociation contributes to anxiety and psychoticism on the Brief Symptom Inventory. Journal of Nervous and Mental Disease, 184, 639-641.

Allen, J. G., Coyne, L., \& Console, D. A. (1997). Dissociative detachment relates to psychotic symptoms and personality decompensation. Comprehensive Psychiatry, 38, 327-334.

American Psychiatric Association. (2013). Diagnostic and statistical manual of mental disorders (5th ed.). Arlington, VA: American Psychiatric Publishing. 
Aydin, Y. E., \& Altindag, A. (2009). Childhood traumatic events and dissociation in university students. International Journal of Psychiatry in Clinical Practice, 13, 25-30.

Barker-Collo, S. L. (2001). Relationship of the Dissociative Experiences Scale to demographics, symptomatology, and coping strategies in a New Zealand student sample. Journal of Trauma \& Dissociation, 2(3), 79-98.

Barker-Collo, S. L., \& Moskowitz, A. K. (2005). Profiles of DES performance in inmate and student samples. Journal of Trauma \& Dissociation, 6(1), 113-124. doi:10.1300/ J229v06n01_07

Bauer, A., \& Power, K. G. (1995). Dissociative experiences and psychopathological symptomatology in a Scottish sample. Dissociation, 8(4), 209-219.

Belli, H., Ural, C., Vardar, M. K., Yesılyurt, S., \& Oncu, F. (2012). Dissociative symptoms and dissociative disorder comorbidity in patients with obsessive-compulsive disorder. Comprehensive Psychiatry, 53, 975-980. doi:10.1016/j.comppsych.2012.02.004

Benjamini, Y., \& Hochberg, Y. (1995). Controlling the false discovery rate: A practical and powerful approach to multiple testing. Journal of the Royal Statistical Society: Series B (Methodological), 57, 289-300.

Bernstein, E., \& Putnam, F. W. (1986). Development, reliability, and validity of a dissociation scale. Journal of Nervous and Mental Disease, 174, 727-735.

Bob, P., Fedor-Freybergh, P., Jasova, D., Bizik, G., Susta, M., Pavlat, J., . . Raboch, J. (2008). Dissociative symptoms and neuroendocrine dysregulation in depression. Medical Science Monitor, 14, CR499-CR504.

Brown, R. P. (1997). Testing for heterogeneity among phenotypic correlations: A comparison of methodsusing MonteCarlosimulations. Genetica,101,67-74.doi:10.1023/A:1018305905597

Carlson, E. B., \& Putnam, F. W. (1993). An update on the Dissociative Experiences Scale. Dissociation, 6(1), 16-27.

Carlson, E. B., Putnam, F. W., \& Ross, C. A. (1993). Validity of the Dissociative Experiences Scale in screening for multiple personality disorder: A multicenter study. The American Journal of Psychiatry, 150, 1030-1036.

Cima, M., Merckelbach, H., Klein, B., Shellbach-Matties, R., \& Kremer, K. (2001). Frontal lobe dysfunctions, dissociation, and trauma self-reports in forensic psychiatric patients. Journal of Nervous and Mental Disease, 189, 188-190.

Ciulla, S., \& Caretti, V. (2012). Trauma, dissociazione, disregolazione, dipendenza [Trauma, dissociation, disregulation, addiction]. Psichiatria e Psicoterapia, 31, 101-119.

Collins, F., \& Jones, K. (2004). Investigating dissociation online: Validation of a web-based version of the Dissociative Experiences Scale. Journal of Trauma \& Dissociation, 5(1), 133-147. doi:10.1300/J229v05n01_08

Conti, L. (1999). Repertorio delle scale valutazione in psichiatria [Psychiatric assessment scales repertory]. Florence, Italy: SEE Editrice Firenze.

Curran-Everett, D. (2000). Multiple comparisons: Philosophies and illustrations. American Journal of Physiology. Regulatory, Integrative and Comparative Physiology, 279(1), R1-R8.

Derogatis, L. R. (1975). Brief Symptom Inventory. Baltimore, MD: Clinical Psychometric Research.

Derogatis, L. R. (1994). Symptom Checklist-90-Revised (SCL-90-R): Administration, scoring and procedures manual (3rd ed.). Minneapolis, MN: National Computer Systems.

Derogatis, L. R. (2011). Symptom Checklist-90-R. Adattamento italiano (I. Sarno, E. Preti, A. Prunas, \& F. Madeddu, Ed.). Firenze, Italy: Giunti O.S.

Derogatis, L. R., \& Melisaratos, N. (1983). The Brief Symptom Inventory: An introductory report. Psychological Medicine, 13, 595-605. 
Dietrich, A. (2003). Characteristics of child maltreatment, psychological dissociation, and somatoform dissociation of Canadian inmates. Journal of Trauma \& Dissociation, 4(1), 81-100. doi:10.1300/J229v04n01 06

Espirito-Santo, H., \& Abreu, J. L. P. (2009). Portuguese validation of the Dissociative Experiences Scale(DES).Journalof Trauma \& Dissociation, 10(1), 69-82.doi:10.1080/15299730802485177

Espirito-Santo, H., \& Costa, M. (2013). Inmates trauma and dissociation. European Psychiatry, 28(Suppl. 1), 1145. doi:10.1016/S0924-9338(13)76555-6

Espirito-Santo, H., Gonçalves, L., Marques, M., Rocha, P., \& Cassimo, S. (2013). Psychoform and somatoform dissociation severity in eating disorders. European Psychiatry, 28(Suppl. 1), 1547. doi:10.1016/S0924-9338(13)76557-X

Evren, C., Cinar, O., Evren, B., Ulku, M., Karabulut, V., \& Umut, G. (2013). The mediator roles of trait anxiety, hostility, and impulsivity in the association between childhood trauma and dissociation in male substance-dependent inpatients. Comprehensive Psychiatry, 54, 158-166. doi:10.1016/j.comppsych.2012.06.013

Fabbri Bombi, A., Bertin, I., Cristante, F., \& Colombo, G. (1996). Un contributo alla standardizzazione della Dissociative Experiences Scale (DES) di Bernstein e Putnam [A contribution for the standardization of the Bernstein and Putnam's Dissociative Experiences Scale (DES)]. Bollettino Di Psicologia Applicata, 219, 39-46.

Foote, B., Smolin, Y., Kaplan, M., Legatt, M. E., \& Lipschitz, D. S. (2006). Prevalence of dissociative disorders in psychiatric outpatients. The American Journal of Psychiatry, 163, 623-629. doi:10.1176/appi.ajp.163.4.623

Garofalo, C., Velotti, P., Zavattini, G. C., Tommasi, M., Romanelli, R., Espirito-Santo, H., \& Saggino, A. (2015). On the factor structure of the Dissociative Experiences Scale: Contribution with an Italian version of the DES-II. Psychiatria $i$ Psychologia Kliniczna - Journal of Psychiatry \& Clinical Psychology, 15(1), 4-12. doi: 10.15557/ PiPK.2015.0001.

Gutiérrez Wang, L., Cosden, M., \& Bernal, G. (2011). Dissociation as a mediator of posttraumatic symptoms in a Puerto Rican university sample. Journal of Trauma \& Dissociation, 12, 358-374. doi:10.1080/15299732.2011.573759

Howell, D. C. (2012). Statistical methods for psychology (7th ed.). Belmont, CA: Cengage Learning.

Lancaster, W., Compton, D., White, N., Bowers, N., \& Herring, P. (1998). MMPI-A and Dissociative Experiences Scale responses of violent and non-violent youth offenders. Journal of Offender Rehabilitation, 26(1-2), 45-52. doi:10.1300/J076v26n01_03

Larøi, F., Billieux, J., Defeldre, A. C., Ceschi, G., \& Van der Linden, M. (2013). Factorial structure and psychometric properties of the French adaptation of the Dissociative Experiences Scale (DES) in non-clinical participants. Revue Europeenne De Psychologie Appliquee, 63, 203-208. doi:10.1016/j.erap.2013.04.004

Levin, R., \& Spei, E. (2004). Relationship of purported measures of pathological and nonpathological dissociation to self-reported psychological distress and fantasy immersion. Assessment, 11, 160-168. doi:10.1177/1073191103256377

Lewis, D. O., Yeager, C. A., Swica, Y., Pincus, J. H., \& Lewis, M. (1997). Objective documentation of child abuse and dissociation in 12 murderers with dissociative identity disorder. The American Journal of Psychiatry, 154, 1703-1710. doi:10.1176/ ajp.154.12.1703

Lewis-Fernandez, R., Garrido-Castillo, P., Bennasar, M. C., Parrilla, E. M., Laria, A. J., Ma, G., $\&$ Petkova, E. (2002). Dissociation, childhood trauma, and ataque de nervios among Puerto Rican psychiatric outpatients. The American Journal of Psychiatry, 159, 1603-1605. 
Lipsanen, T., Saarijärvi, S., \& Lauerma, H. (2003). The Finnish version of the Dissociative Experiences Scale-II (DES-II) and psychiatric distress. Nordic Journal of Psychiatry, 57, 17-22. doi:10.1080/08039480310000211

Löffler-Stastka, H., Szerencsics, M., \& Blüml, V. (2009). Dissociation, trauma, affect regulation and personality in patients with a borderline personality organization. Bulletin of the Menninger Clinic, 73(2), 81-98. doi:10.1521/bumc.2009.73.2.81

Lysaker, P. H., \& LaRocco, V. A. (2008). The prevalence and correlates of trauma-related symptoms in schizophrenia spectrum disorder. Comprehensive Psychiatry, 49, 330-334. doi:10.1016/j.comppsych.2007.12.003

Maaranen, P. (2008). Dissociation in the Finnish general population. Faculty of Medicine of the University of Kuopio, Kuopio, Finland.

Maaranen, P., Tanskanen, A., Hintikka, J., Honkalampi, K., Haatainen, K., Koivumaahonkanen, H., \& Viinamäki, H. (2008). The course of dissociation in the general population: A 3-year follow-up study. Comprehensive Psychiatry, 49, 269-274. doi:10.1016/j.comppsych.2007.04.010

Maaranen, P., Tanskanen, A., Honkalampi, K., Haatainen, K., Hintikka, J., \& Viinamäki, H. (2005). Factors associated with pathological dissociation in the general population. The Australian \& New Zealand Journal of Psychiatry, 39, 387-394. doi:10.1111/j.14401614.2005.01586.x

Martínez-Taboas, A., \& Bernal, G. (2000). Dissociation, psychopathology, and abusive experiences in a nonclinical Latino university student group. Cultural Diversity \& Ethnic Minority Psychology, 6, 32-41.

McLeod, H., Byrne, M., \& Aitken, R. (2004). Automatism and dissociation: Disturbances of consciousness and volition from a psychological perspective. International Journal of Law and Psychiatry, 27, 471-487. doi:10.1016/j.ijlp.2004.06.007

Mitchell, J. A. (2006). Symptoms of dissociation in a forensic population. Journal of Orthomolecular Medicine, 21, 85-94.

Modestin, J., Ebner, G., Junghan, M., \& Erni, T. (1996). Dissociative experiences and dissociative disorders in acute psychiatric inpatients. Comprehensive Psychiatry, 37, 355-361.

Moskowitz, A. K. (2004). Dissociation and violence: A review of the literature. Trauma, Violence, \& Abuse, 5, 21-46. doi:10.1177/1524838003259321

Moskowitz, A. K., Barker-Collo, S., \& Ellson, L. (2005). Replication of dissociation-psychosis link in New Zealand students and inmates. Journal of Nervous and Mental Disease, 193, 722-727. doi:10.1097/01.nmd.0000185895.47704.62

Mulder, R. T., Beautrais, A. L., Joyce, P. R., \& Fergusson, D. M. (1998). Relationship between dissociation, childhood sexual abuse, childhood physical abuse, and mental illness in a general population sample. The American Journal of Psychiatry, 155, 806-811.

Nilsson, D., Gustafsson, P. E., \& Svedin, C. G. (2010). Self-reported potentially traumatic life events and symptoms of post-traumatic stress and dissociation. Nordic Journal of Psychiatry, 64, 19-26. doi:10.3109/08039480903264846

Oedegaard, K. J., Neckelmann, D., Benazzi, F., Syrstad, V. E. G., Akiskal, H. S., \& Fasmer, O. B. (2008). Dissociative experiences differentiate bipolar-II from unipolar depressed patients: The mediating role of cyclothymia and the Type A behaviour speed and impatience subscale. Journal of Affective Disorders, 108, 207-216. doi:10.1016/j.jad.2007.10.018

Poythress, N. G., Skeem, J. L., \& Lilienfeld, S. O. (2006). Associations among early abuse, dissociation, and psychopathy in an offender sample. Journal of Abnormal Psychology, 115, 288-297. doi:10.1037/0021-843X.115.2.288 
Ross, C. A., Heber, S., Norton, G., \& Anderson, D. (1989). The dissociative disorders interview schedule: A structured interview. Dissociation, 2(3), 69-189.

Ross, C. A., Joshi, S., \& Currie, R. (1991). Dissociative experiences in the general population: A factor analysis. Hospital \& Community Psychiatry, 42(3), 297-301.

Rufer, M., Fricke, S., Held, D., Cremer, J., \& Hand, I. (2005). Dissociation and symptom dimensions of obsessive-compulsive disorder. European Archives of Psychiatry \& Clinical Neuroscience, 256, 146-150. doi:10.1007/s00406-005-0620-8

Ruiz, M. A., Poythress, N. G., Lilienfeld, S. O., \& Douglas, K. S. (2008). Factor structure and correlates of the Dissociative Experiences Scale in a large offender sample. Assessment, 15, 511-521. doi:10.1177/1073191108315548

Sar, V., Koyuncu, A., Ozturk, E., Yargic, L. I., Kundakçi, T., Yazici, A., . . Aksüt, D. (2007). Dissociative disorders in the psychiatric emergency ward. General Hospital Psychiatry, 29, 45-50. doi:10.1016/j.genhosppsych.2006.10.009

Sar, V., Taycan, O., Bolat, N., Özmen, M., Duran, A., Ozturk, E., \& Ertem-Vehid, H. (2010). Childhood trauma and dissociation in schizophrenia. Psychopathology, 43, 33-40. doi:10.1159/000255961

Schäfer, I., Fisher, H. L., Aderhold, V., Huber, B., Hoffmann-Langer, L., Golks, D., . . . Harfst, T. (2011). Dissociative symptoms in patients with schizophrenia: Relationships with childhood trauma and psychotic symptoms. Comprehensive Psychiatry, 53, 364-371. doi:10.1016/j.comppsych.2011.05.010

Schäfer, I., Reininghaus, U., Langeland, W., Voss, A., Zieger, N., Haasen, C., \& Karow, A. (2007). Dissociative symptoms in alcohol-dependent patients: Associations with childhood trauma and substance abuse characteristics. Comprehensive Psychiatry, 48, 539-545. doi:10.1016/j.comppsych.2007.05.013

Simões, S., Espirito-Santo, H., Jesus, M., \& Marques, M. (2014). Traumatic and dissociative experiences in a sample of Portuguese patients with schizophrenia and bipolar disorder. European Psychiatry, 29(Suppl. 1), 1.

Snow, M. S., \& Beckman, D. (1996). Results of the Dissociative Experiences Scale in a jail population. Dissociation, 9, 98-103.

Somer, E., Altus, L., \& Ginzburg, K. (2010). Dissociative psychopathology among opioid use disorder patients: Exploring the "chemical dissociation" hypothesis. Comprehensive Psychiatry, 51, 419-425. doi:10.1016/j.comppsych.2009.09.007

Spitzer, C., Barnow, S., Grabe, H. J., Klauer, T., Stieglitz, R.-D., Schneider, W., \& Freyberger, H. J. (2006). Frequency, clinical and demographic correlates of pathological dissociation in Europe. Journal of Trauma \& Dissociation, 7(1), 51-62. doi:10.1300/J229v07n01_05

Spitzer, C., Dudeck, M., Liss, H., Orlob, S., Gillner, M., \& Freyberger, H. J. (2001). Posttraumatic stress disorder in forensic inpatients. Journal of Forensic Psychiatry \& Psychology, 12, 63-77. doi:10.1080/09585180121757

Spitzer, C., Freyberger, H. J., \& Stieglitz, R.-D. (1998). Adaptation and psychometric properties of the German version of the Dissociative Experience Scale. Journal of Traumatic Stress, 11, 799-809.

Spitzer, C., Liss, H., Dudeck, M., Orlob, S., Gillner, M., Hamm, A., \& Freyberger, H. J. (2003). Dissociative experiences and disorders in forensic inpatients. International Journal of Law and Psychiatry, 26, 281-288. doi:10.1016/S0160-2527(03)00038-4

Steinberg, M., Cicchetti, D., \& Buchanan, J. (1993). Clinical assessment of dissociative symptoms and disorders: The Structured Clinical Interview for DSM-IV Dissociative Disorders (SCID-D). Dissociation, 6(1), 3-15. 
Stockdale, G. D., Gridley, B. E., Balogh, D. W., \& Holtgraves, T. (2002). Confirmatory factor analysis of single and multiple-factor competing models of the Dissociative Experiences Scale in a nonclinical sample. Assessment, 9, 94-106. doi:10.1177/1073191102009001011

Van IJzendoorn, M. H., \& Schuengel, C. (1996). The measurement of dissociation in normal and clinical populations: Meta-analytic validation of the Dissociative Experiences Scale (DES). Clinical Psychology Review, 16, 365-382.

Vogel, M., Spitzer, C., Barnow, S., Freyberger, H. J., \& Grabe, H. J. (2006). The role of trauma and PTSD-related symptoms for dissociation and psychopathological distress in inpatients with schizophrenia. Psychopathology, 39, 236-242. doi:10.1159/000093924

Walker, A. (2002). Dissociation in incarcerated juvenile male offenders - A pilot study in Australia. Psychiatry, Psychology and Law, 9, 56-61. doi:10.1375/pplt.2002.9.1.56

Watson, D. (2001). Dissociations of the night: Individual differences in sleep-related experiences and their relation to dissociation and schizotypy. Journal of Abnormal Psychology, 110, 526-535. doi:10.1037/0021-843X.110.4.526

Xiao, Z., Yan, H., Wang, Z., Zou, Z., Xu, Y., Chen, J, . . Keyes, B. B. (2006). Trauma and dissociation in China. The American Journal of Psychiatry, 163, 1388-1391. doi:10.1176/ appi.ajp.163.8.1388

Yoshizumi, T., Murase, S., Murakami, T., \& Takai, J. (2007). Dissociation as a mediator between perceived parental rearing style and depression in an adult community population using college students. Personality and Individual Differences, 43, 353-364. doi:10.1016/j. paid.2006.12.010 